\title{
Study on the decomposition of vehicle evaporative emissions
}

\author{
Kun Liao ${ }^{1, *}$, Ni Zhang ${ }^{1}$, Lingyun Wei ${ }^{1}$, Wen Sun ${ }^{1}$, and Shenghua $\mathrm{Qu}^{2}$ \\ ${ }^{1}$ Test and Capability support Department of technical center of Dongfeng Automobile Group Co., \\ Ltd,Wuhan City,430058, China \\ ${ }^{2}$ Powertrain Development Department of technical center of Dongfeng Automobile Group Co., \\ Ltd, Wuhan City,430058, China
}

Keywords: evaporative pollutant emission, fuel hydrocarbon, non fuel hydrocarbon.

\begin{abstract}
With the further tightening of light vehicle emission regulations, the emission limit of evaporative pollutants is reduced from $2.0 \mathrm{~g} /$ test to $0.7 \mathrm{~g} / \mathrm{test}$ from the fifth stage to the sixth stage in China. The definition of evaporative pollutants in the regulation refers to the hydrocarbon loss from the fuel system of the vehicle. Through the actual evaporation test, it is found that the tested emissions include not only the hydrocarbon emissions from the fuel system, but also the hydrocarbon emissions from the non fuel system. In this study, an experimental study on evaporative pollutants was carried out for a vehicle and its components developed by Dongfeng Motor Company. The results show that the hydrocarbon emission from fuel system accounts for $21 \%$ of the total hydrocarbon emission. In order to reduce the emission of evaporative pollutants, we can start from two aspects: one is to improve the design of fuel system; the other is to carry out specific pretreatment for non fuel system.
\end{abstract}

\section{Preface}

Cars bring convenience to our life, but also cause certain pollution to the environment. Hydrocarbon, as one of the pollutants, refers to the unburned part of engine exhaust gas, including fuel evaporation and leakage in fuel supply system. Only when the content of hydrocarbon is very high, can it affect the human body. Generally speaking, it has little effect, but it is an important component of photochemical smog. The main factors that cause hydrocarbon pollution to the environment are exhaust emissions, crankcase emissions and fuel evaporation emissions. Among them, the fuel vapor emission is caused by the fuel vapor overflow and the fuel volatilization in the fuel tank.

Evaporative pollutants refer to the hydrocarbon vapor lost from the fuel (gasoline) system of the vehicle except for the exhaust pipe of the vehicle, including: (1) loss of exhalation in the fuel tank (loss of air exchange): the hydrocarbon emitted due to the temperature change in the fuel tank is expressed in $C_{1} H_{2.33}$ equivalent. (2) Hot soak loss: the hydrocarbon

\footnotetext{
*Corresponding author: liaokun@dfmc.com.cn
} 
emitted from the fuel system of a stationary vehicle after driving for a period of time, expressed in $C_{1} H_{2.20}$ equivalent .

With the change of emission regulations from the fifth stage of China to the sixth stage of China, the test procedures of evaporative pollutant emission test become more stringent. For example, the test desorption condition is changed from the original NEDC to the low, medium, high and high working conditions of WLTC, the times of oil discharge and refueling are increased once, and the temperature of hot soak test is increased from the original fluctuation range of $23{ }^{\circ} \mathrm{C}-31{ }^{\circ} \mathrm{C}$ to the fluctuation range of $33{ }^{\circ} \mathrm{C}-41{ }^{\circ} \mathrm{C}$ with the starting temperature of $38{ }^{\circ} \mathrm{C}$. At the same time, the evaporative emission limit is increased from $2.0 \mathrm{~g} /$ test to $0.7 \mathrm{~g} /$ test, and the requirements of ORVR emission control are also increased. In the actual test process of evaporative emission test, the evaporative emission pollutants detected by the test equipment are mainly divided into two parts: the first part refers to the hydrocarbon vapor generated from the fuel vapor volatilization of the fuel system composed of fuel tank, carbon canister and refueling pipeline; the second part refers to the hydrocarbon emission of other non fuel systems, such as automobile interior parts and automobiles volatile hydrocarbons emitted from tires, automotive electronic and electrical systems, etc. However, under the existing laboratory test conditions, it is impossible to separate these hydrocarbons emitted by non fuel system from the evaporative emission test. Therefore, it is necessary to consider fuel system and non fuel system to reduce vehicle evaporative emission pollutants.

\section{Test method of evaporative pollutant emission}

In this study, a vehicle model developed by Dongfeng Motor Company was tested for evaporative pollutants. The detailed model and engine details are shown in Table $1 \& 2$. Table 3 shows the performance parameters of the fuel system of this model.

The test equipment in this study includes: shed evaporation chamber, chassis dynamometer, carbon tank pretreatment equipment, etc. The main test equipment details are shown in Table 4.

Table 1. Main parameters.

\begin{tabular}{cccc}
\hline Curb weight & Transmission model & Tire type & Sliding resistance \\
\hline $1273 \mathrm{~kg}$ & DCT & 205/50ZR17 & $\mathrm{Y}=0.0312 \mathrm{~V}^{2}+0.6585 \mathrm{~V}+101$. \\
& & & 1 \\
\hline
\end{tabular}

Table 2. Main performance parameters of on board 1.5L engine.

\begin{tabular}{ccccc}
\hline $\begin{array}{c}\text { Rated } \\
\text { power }\end{array}$ & $\begin{array}{c}\text { Maximum } \\
\text { speed }\end{array}$ & idling & Maximum torque & $\begin{array}{c}\text { Minimum specific fuel } \\
\text { consumption at full load }\end{array}$ \\
\hline $\begin{array}{c}98 \mathrm{~kW} / 5500 \\
\mathrm{r} / \mathrm{min}\end{array}$ & $6000 \mathrm{r} / \mathrm{min}$ & $\begin{array}{c}750 \pm 50 \mathrm{r} / \\
\mathrm{min}\end{array}$ & $\begin{array}{c}196 \mathrm{~N} . \mathrm{m} / 1800 \sim \\
4500 \mathrm{r} / \mathrm{min}\end{array}$ & $280 \mathrm{~g} / \mathrm{kW} \cdot \mathrm{h}$ \\
\hline
\end{tabular}

Table 3. Main performance parameters of fuel system.

\begin{tabular}{ccccc}
\hline Tank volume & $\begin{array}{c}\text { Fuel tank } \\
\text { material }\end{array}$ & $\begin{array}{c}\text { Volume of } \\
\text { carbon } \\
\text { canister }\end{array}$ & $\begin{array}{c}\text { Working capacity of } \\
\text { carbon canister }\end{array}$ & $\begin{array}{c}\text { Activated carbon } \\
\text { materials }\end{array}$ \\
\hline $51 \mathrm{~L}$ & Plastic & $1.7 \mathrm{~L}$ & $4.7 \mathrm{~g} / 100 \mathrm{ml}$ & BAX LBE $/ 1500$ \\
\hline
\end{tabular}

Table 4. Main test equipment.

\begin{tabular}{cc}
\hline Equipments name & Suppliers \\
\hline Shed evaporation chamber & VT-SHED Fullsize of AVL Company \\
\hline Chassis dynamometer & MAHA Company \\
\hline Carbon tank pretreatment equipment & M+P Company \\
\hline
\end{tabular}


The on-board refueling vapor recovery system (ORVR system) of the test sample vehicle is an integrated control system of vehicle fuel evaporation pollutants, that is, the vehicle uses the same hardwares to control the guidance, storage and desorption of refueling emissions and diurnal air exchange emissions. The ORVR system is installed on the vehicle. Its main function is to absorb the fuel vapor generated by fuel evaporation in the fuel tank during vehicle refueling, driving and parking, and store it in the carbon canister; When the engine is running, the carbon canister desorption valve is opened, and the engine intake manifold generates negative pressure. Fresh air flows into the engine from the carbon canister air port, and enters the engine through the desorption valve from the carbon canister desorption port, and the fuel vapor in the carbon canister is blown into the engine to participate in combustion. The principle of ORVR system is shown in Figure 1.

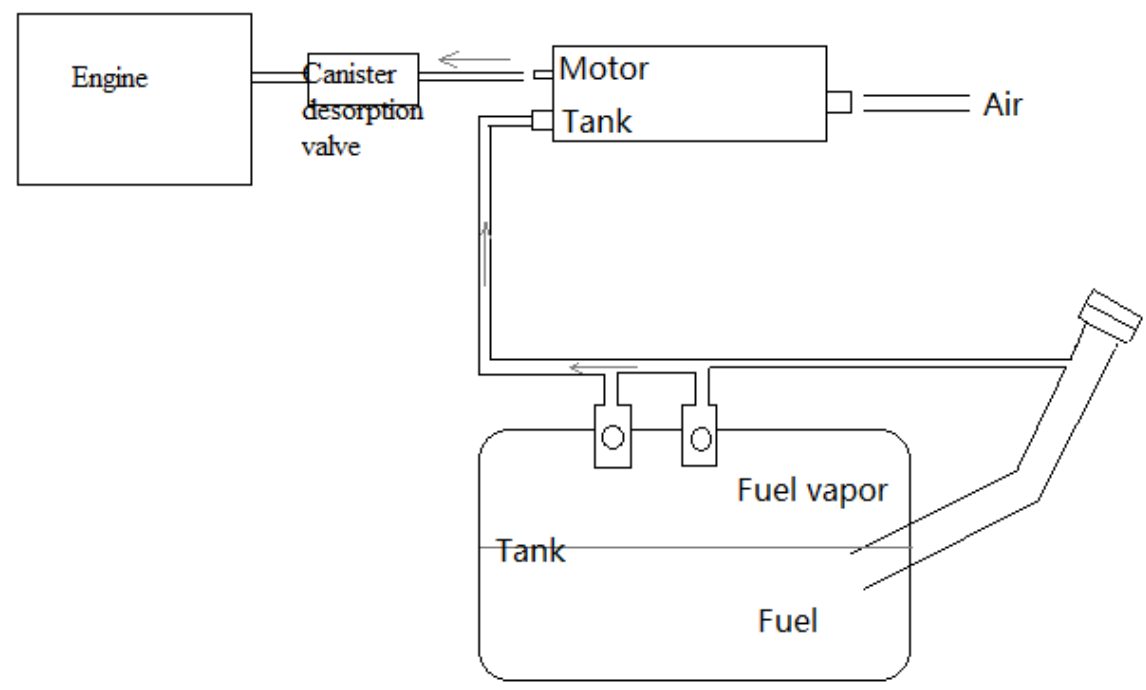

Fig. 1. Working principle of ORVR system.

According to Appendix F of GB 18352.6-2016 "Limits and measurement methods for emissions from light-duty vehicles(CHINA 6)",the evaporation test process is shown in Figure 2. Among them, nirco system is a kind of non integral control system, and the main purpose of activated carbon canister design is to absorb only the oil and gas produced during refueling. The fuel vapor generated by other non refueling processes is stored in the fuel tank or discharged to the engine for combustion instead of stored in the carbon canister ${ }^{[1]}$. 


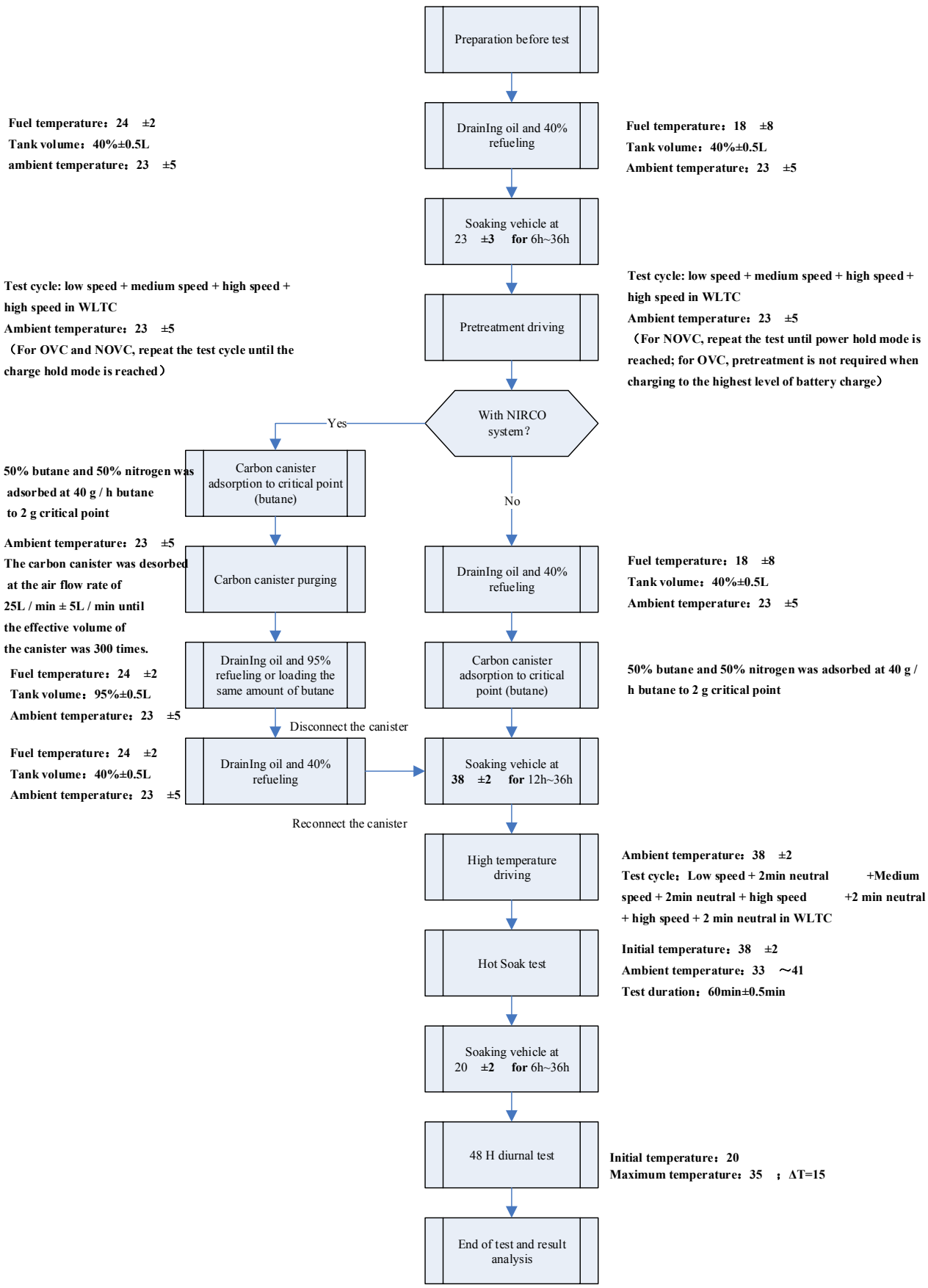

Fig. 2. Test process of evaporative pollutants emission from gasoline fueled vehicles.

\section{Test results and analysis of evaporation pollutants}

\subsection{Vehicle evaporative emission test}


According to the above test process, the evaporation pollutants of the whole vehicle were measured for many times, and the average value was obtained. The test results are shown in Table 5 .

Table 5. Test results of vehicle evaporative emission.

\begin{tabular}{ccc}
\hline HotSoak & Diurnal (24H) & Diurnal (48H) \\
\hline $0.0635 \mathrm{~g}$ & $0.1599 \mathrm{~g}$ & $0.1382 \mathrm{~g}$
\end{tabular}

According to Appendix F of GB 18352.6-2016 "Limits and measurement methods for emissions from light-duty vehicles(CHINA 6)", the total mass of vehicle hydrocarbon evaporative emission is taken as:

$$
M_{\text {总 }}=M_{D I}+M_{H S}
$$

where:

$M_{\text {Total }}$ - total mass of hydrocarbons emitted by vehicle evaporation, g;

$M_{D I}$-hydrocarbon emission mass during diurnal test, $\mathrm{g}\left(M_{D I}\right.$ is the bigger one of $M_{H C, 24}$ and $\left.M_{H C, 48}\right)$;

$M_{H C, 24}$ - mass of hydrocarbon emission during hot soak test, $\mathrm{g}^{[1]}$.

Therefore, the total evaporative emission mass of the vehicle is:

$$
0.0635 \mathrm{~g}+0.1599 \mathrm{~g}=0.2234 \mathrm{~g}
$$

According to 5.3.4 of GB 18352.6-2016 "Limits and measurement methods for emissions from light-duty vehicles(CHINA 6)", the test results shall be added and corrected for deterioration. The total correction of deterioration is as follow:

$$
0.2234 \mathrm{~g}+0.06 \mathrm{~g}=0.2834 \mathrm{~g} \text {, }
$$

The final result of the vehicle evaporative pollutant is $0.2834 \mathrm{~g}$, which is less than the limit value required by the sixth national regulation of evaporative emission test, i.e. $0.7 \mathrm{~g}$. Therefore, the hydrocarbon evaporative emissions of the test sample vehicle meet the development requirements.

\subsection{Vehicle evaporative emission decomposition test}

In order to further verify the influence of vehicle components on vehicle evaporative emissions, it has practical significance to reduce vehicle evaporative emissions in the later stage. The whole vehicle was disassembled into fuel system, powertrain system, tire system, body system, interior trim, suspension system and exterior trim parts for test. During disassembly, the system shall be kept intact, and all connecting pipelines shall be consistent with the state of the whole vehicle.

In this study, the diurnal air change test in Appendix F of GB 18352.6-2016 " Limits and measurement methods for emissions from light-duty vehicles(CHINA 6)" was carried out. The test temperature was $20{ }^{\circ} \mathrm{C}-35{ }^{\circ} \mathrm{C}-20{ }^{\circ} \mathrm{C}$, and the test time was 24 hours. The average value of each component was obtained by measuring several times. The comparison chart of test data is shown in Figure 3 below. It can be found from Figure 3 that the top three components with the highest emissions are tire system, fuel system and powertrain system. 


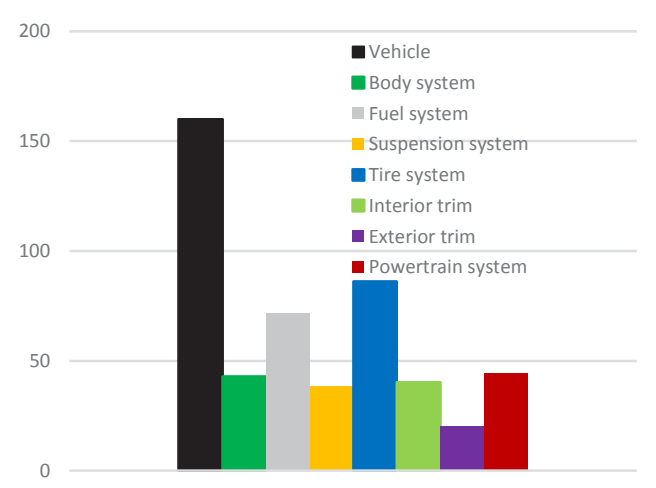

Fig. 3. Column chart of evaporative emission results of various components.

The emission ratio of each component is shown in Figure 4. The evaporative emissions of the fuel system account for $21 \%$ of the total evaporative emissions of all components. The rest of the evaporative pollutants come from other parts of the vehicle. It can be seen that in the vehicle evaporative emission test, the proportion of non fuel hydrocarbon emissions is large. Among them, the hydrocarbon emission ratio of tire system is $25 \%$, which is higher than that of fuel system with $21 \%$ hydrocarbon emission.

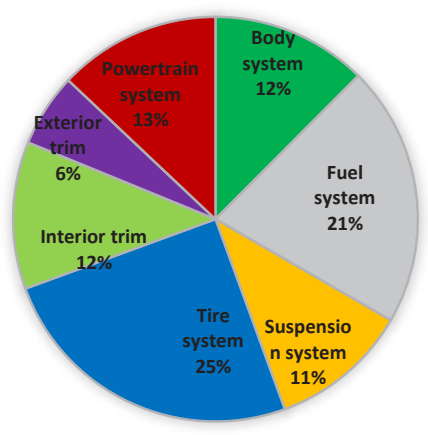

Figure 4. Pie chart of evaporative emission results of various components.

Therefore, in order to control the evaporative emissions, we should not only reduce the hydrocarbon emissions produced by the fuel system, but also control the vehicle hydrocarbons emissions of the components other than the fuel system.

\section{Control methods of evaporative emission pollutants}

Through the analysis of the test results, we can start from the following four aspects to reduce the vehicle evaporative emission pollutants:

\subsection{Optimization design of carbon canister}

Carbon canister is the core component of vehicle evaporative emission control system, which directly affects the performance of vehicle evaporation system. Different vehicles have different desorption capacity under specific desorption conditions. Improving the adsorption and desorption capacity of carbon canister can make the carbon canister have enough residual 
working capacity to absorb fuel vapor during hot soak test and diurnal test, so as to ensure that the fuel vapor will not overflow into the evaporation chamber and affect the evaporation test results.

\subsubsection{Optimization of adsorption capacity of carbon canister}

\section{1) Design of carbon powder for carbon canister}

Carbon canister adsorption refers to the adsorption of hydrocarbon molecules in fuel vapor between the voids of activated carbon powder. Due to van der Waals force, when hydrocarbon molecules pass through the pores of carbon powder, they will be absorbed by activated carbon powder, which plays a role in purifying fuel vapor. The use of carbon powder with more pores, larger surface area and better adsorption performance can make the carbon canister have better working capacity, but the production cost will increase accordingly. Therefore, different kinds of carbon powder can be considered to be arranged in layers to achieve the goal of balancing the cost and the performance of the carbon canister. Bax $1500+\mathrm{LBE}$ is the carbon powder combination of the carbon canister of the test vehicle, as shown in Figure 5. The test results show that the hydrocarbon emission of the fuel system accounts for $21 \%$ of the total evaporative emission, and the hydrocarbon emission reduction effect is good. He Yanbin, the technical center of Great Wall Motors Co., Ltd., also confirmed that the layered design of different kinds of carbon powder is effective for improving the working performance of carbon canister in the research which is listed in the references.

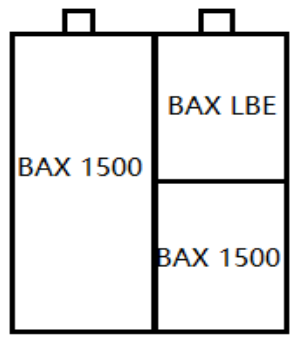

Fig. 5. Schematic diagram of carbon powder combination in carbon canister of test vehicle in this study.

2) Design of carbon canister structure

In order to improve the adsorption performance of carbon canister, we can also consider the structure of carbon canister, such as properly increasing the volume of carbon canister, increasing the inner diameter of pipeline, and increasing the length diameter ratio of carbon canister, so as to make the fuel fully contact with activated carbon, so as to improve the adsorption capacity. However, the structural dimension design should meet the technical requirements of the ventilation resistance performance of the control system according to HJ/T 390-2007, to avoid the influence of excessive ventilation resistance on the working capacity of carbon canister.

\subsubsection{Optimization of vehicle desorption}

In addition to the working ability of the carbon canister itself, it is also related to the design of the whole vehicle. During the desorption process, heating the air port of the carbon canister is adopted to improve the inlet temperature of the carbon canister, heat the activity of the hydrocarbon molecules in the carbon canister, overcome the van der Waals force between the hydrocarbon molecules and the carbon powder, and make the hydrocarbon molecules 
more easily separated from the carbon canister to meet the requirements of increasing the desorption amount. In addition, due to the strict requirements of laws and regulations on emission limits of China's sixth stage, the small displacement and supercharged engines are popular, which makes the carbon canister desorption amount smaller under the cycle condition. Therefore, it can be optimized by modifying the engine calibration data, for example, modifying the duty cycle of the carbon canister solenoid valve to control the opening time and opening size of the carbon canister, or increasing the desorption amount by adding venturi tube or flushing pump to increase the negative pressure of desorption pipe, but the desorption amount of carbon canister should not be designed too large to avoid the excessive concentration of engine mixture. Therefore, it is necessary to increase the desorption amount of carbon canister as far as possible on the premise of meeting the main performance of the engine.

\subsection{Design of fuel tank}

In today's advocating energy conservation and emission reduction, the selection of plastic fuel tank is undoubtedly a good method for vehicle lightweight. According to GB 182962019 " Safety property requirements and test methods for automobile fuel tank and its installation ", the fuel permeability test requirements of plastic fuel tank are as follows: 1) The test oil is the reference fuel specified in GB 18352.6-2016 " Limits and measurement methods for emissions from light-duty vehicles(CHINA 6)", or the current reference fuel for vehicle emission test.,Gasoline shall be used in the fuel tank of vehicles equipped with spark ignition engines.

2) Pretreatment before test: inject test fuel into the fuel tank to reach $50 \%$ of the rated capacity, and do not seal the fuel tank, It is stored at $40{ }^{\circ} \mathrm{C} \pm 2{ }^{\circ} \mathrm{C}$ until the fuel loss per unit time is stable, but not more than 4 weeks.

3) Empty the fuel tank, inject new test fuel to $50 \%$ of the rated capacity, seal the fuel tank and store it at $40{ }^{\circ} \mathrm{C} \pm 2{ }^{\circ} \mathrm{C}$. When the internal temperature of the fuel tank reaches the test temperature, release the internal pressure of the fuel. The test cycle is 8 weeks, and the fuel evaporation is measured. Determine the average evaporation per 24 hours. According to the standard, the fuel evaporation should not be more than $20 \mathrm{~g} / 24 \mathrm{~h}$.

4) If the fuel evaporation exceeds the standard value according to the test method in 3 ), adjust the ambient temperature to $23{ }^{\circ} \mathrm{C} \pm 2{ }^{\circ} \mathrm{C}$, and repeat the test on the same fuel tank according to the same test method. According to the standard, the fuel evaporation should not be greater than $10 \mathrm{~g} / 24 \mathrm{~h}$.

5) If the vehicle equipped with fuel tank meets the limit conditions of evaporative emission test results specified in 5.3.4 of GB 18352.6-2016 "Limits and measurement methods for emissions from light-duty vehicles(CHINA 6)", the fuel tank is considered to meet the fuel permeability requirements .

In the actual whole evaporation test process, the test sample vehicle shall be operated under the conditions of $23{ }^{\circ} \mathrm{C} \pm 3{ }^{\circ} \mathrm{C}$ immersion, $23{ }^{\circ} \mathrm{C} \pm 3{ }^{\circ} \mathrm{C}$ carbon canister desorption, oil discharge and refueling, carbon tank breakdown, $38{ }^{\circ} \mathrm{C} \pm 2{ }^{\circ} \mathrm{C}$ high temperature immersion, $38{ }^{\circ} \mathrm{C} \pm 2{ }^{\circ} \mathrm{C}$ high temperature desorption operation, etc. Among them, the carbon canister not only absorbs the fuel vapor generated during the refueling process, but also the volatile fuel vapor from the fuel tank during the immersion period. On the one hand, excessive fuel volatile vapor will lead to premature saturation of carbon canister, which will affect the absorption of fuel vapor by carbon canister during hot soak test and diurnal test. At the same time, due to the relatively weak van der Waals force between hydrocarbon molecules and activated carbon powder, when the fuel vapor flow into the canister increases, some hydrocarbon molecules originally adsorbed by activated carbon 
powder will be desorbed, this part of hydrocarbon molecules will flow out of the canister through the atmospheric port. Therefore, the fuel tank should be designed to minimize the fuel evaporation in the fuel permeability test.

On the premise of meeting the repuirements of GB 18296-2019 "Safety property requirements and test methods for automobile fuel tank and its installation"and reasonable vehicle layout, the evaporation surface area in the fuel tank shall be appropriately reduced, such as the design of multi-layer fuel tank.

In addition, some successful technical strategies can be adopted at home and abroad, such as: using gasoline with low vapor pressure; adopting heat insulation measures to reduce the heat radiation of vehicle heat source to the fuel tank to reduce fuel evaporation; reasonably designing the internal space structure of the fuel tank and the appropriate steam line resistance along the way to ensure that the fuel evaporation in the fuel tank reaches evaporation saturation under appropriate conditions, to reduce the total evaporation of the fuel in the tank; the maximum evaporation capacity is controlled by changing the pressure in the upper space of the fuel tank.

\subsection{Pretreatment of non fuel system}

Automobile parts and interior decoration materials will release volatile organic compounds, such as: plastic interior parts, electronic and electrical parts, seat fabrics, rubber tires, sealing strips, body paint, thermal insulation materials, adhesives, etc., which will release organic solvents, additives, additives and other volatile substances, mainly benzene, toluene, formaldehyde, acetone, dimethyl Benzene, hydrocarbon, halogenated hydrocarbon, etc. The volatile hydrocarbons will directly affect the evaporative emission value. The results of this study show that the evaporative emission value of other systems except the fuel system accounts for $79 \%$ of the total emission value of all components, as shown in Figure 4 . It can be seen that this part of hydrocarbons has a great impact on the results of vehicle evaporative emissions. Therefore, we can speed up the volatilization of volatile hydrocarbons by means of window opening, ventilation, baking and other pretreatment methods to reduce the emission of non fuel hydrocarbons. Qiu Xuetang of Guangdong Automobile Testing Center Co., Ltd. has studied the baking pretreatment technology in the research. The research shows that the strategy of baking at $60{ }^{\circ} \mathrm{C}$ for $192 \mathrm{~h}$ can reduce $60 \%$ of the whole vehicle's non fuel evaporation emission and make the volatile hydrocarbons reach a stable level. In this study, no special pretreatment was carried out on the test sample vehicle, and the proportion of non fuel hydrocarbon was up to $79 \%$. It shows that the special baking pretreatment can effectively reduce the vehicle evaporative emission level.

\section{Conclusion}

In this paper, the evaporative emissions of vehicle and decomposed components are studied, and the main conclusions are as follows:

1. The evaporative emission of Dongfeng Motor Company is $0.2834 \mathrm{~g}$, which meets the national limit;

2. The non fuel system evaporative emissions account for $79 \%$ of the total vehicle evaporative emissions. We can reduce non fuel evaporative emissions by special pretreatment of the vehicle's non fuel system.

3. The evaporative emission of fuel system can be reduced by improving the design of carbon canister and fuel tank.

In conclusion, except for the fuel system, other components of the vehicle account for a large proportion of hydrocarbon emissions in the vehicle evaporative emission test. In order 
to reduce vehicle evaporative emissions, the vehicle fuel system design and component materials should be optimized and improved.

\section{Reference}

1. Ministry of environmental protection of the people's Republic of China, General Administration of quality supervision, inspection and Quarantine of the people's Republic of China.GB 18352.6-2016 Limits and measurement methods for emissions from light-duty vehicles(CHINA 6) [S].

2. 何彦涁, 李长江. 国VI法规下的炭罐设计 [J]. 汽车工程师, 2018(1)：37-40.

3. Ministry of environmental protection of the people's Republic of China. HJ/T390-2007 Technical requirement for environmental protection product Control system of fuel evaporative pollutants from vehicle with petrol engine $[\mathrm{S}]$

4. State Administration of market supervision and Administration, National Standardization Management Committee.GB 18296-2019 Safety property requirements and test methods for automobile fuel tank and its installation [S]

5. 高俊华. 减少整车蒸发排放技术的技术策略研究 [D]. 吉林：吉林大学, 2007 .

6. State Environmental Protection Administration. HJ/T 400-2007 Determination of volatile organic compounds and carbonyl compounds in cabin of vehicles [S]

7. 丘雪棠. 烘烤预处理技术对整车非燃油蒸发排放影响的研究 [J]. 汽车实用技术, 2020 (10) : 196-198. 